\title{
Sunlight-Driven Combustion Synthesis of Defective Metal Oxide Nanostructures with Enhanced Photocatalytic Activity
}

\author{
Abdo Hezam, ${ }^{\dagger}$ K. Namratha, ${ }^{*}$ Deepalekshmi Ponnamma, ${ }^{\S}$ Q. A. Drmosh, $, *, \|$ \\ Adel Morshed Nagi Saeed, ${ }^{\perp}$ Kishor Kumar Sadasivuni, ${ }^{\S}$ and Kullaiah Byrappa, ${ }^{*} \oplus$ \\ ${ }^{\dagger}$ Center for Materials Science and Technology, University of Mysore, Vijnana Bhavan, Manasagangothiri, Mysuru 570006, India \\ ${ }^{\ddagger}$ DOS in Earth Science, University of Mysore, Manasagangothiri, Mysuru 570006, India \\ ${ }^{\S}$ Center for Advanced Materials, Qatar University, P.O. Box 2713, Doha, Qatar \\ "Center of Research Excellence in Nanotechnology, King Fahd University of Petroleum and Minerals, Dhahran 31261, Saudi Arabia \\ ${ }^{\perp}$ Department of Polymer Science and Technology, Sri Jayachamarajendra College of Engineering, JSS Science \& Technology \\ University, Mysuru 570006, India \\ \#Adichunchanagiri University, N.H. 75, B. G. Nagara, Mandya, 571448, India
}

Supporting Information

\begin{abstract}
Synthesis of metal oxide nanostructures through combustion routes is a promising technique owing to its simplicity, rapidity, scalability, and cost-effectiveness. Herein, a sunlight-driven combustion approach is developed to synthesize pristine metal oxides and their heterostructures. Sunlight, a sustainable energy source, is used not only to initiate the combustion reaction but also to create oxygen vacancies on the metal oxide surface. $\mathrm{ZnO}$ nanostructures are successfully synthesized using this novel approach, and the products exhibit higher photocatalytic activity in the decomposition of methyl orange (MO) than $\mathrm{ZnO}$ nanostructures synthesized by the conventional methods. The higher photocatalytic activity is due to the narrower band gap, higher porosity, smaller and more uniform particle size, surface oxygen vacancies, as well as the enhanced exciton dissociation efficiency induced by the sunlight. Porous $\mathrm{Fe}_{3} \mathrm{O}_{4}$ nanostructures are also prepared using this environmentally

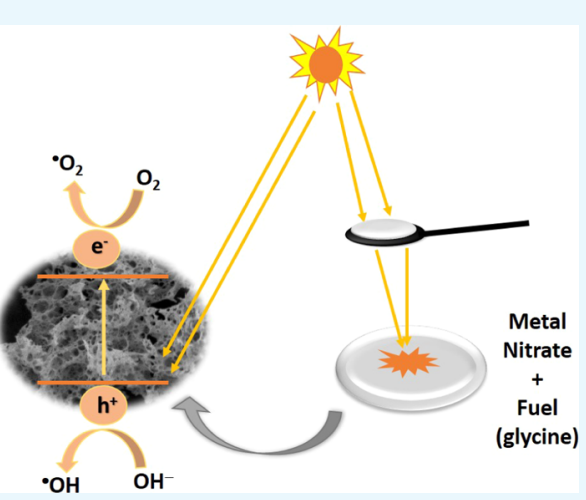
benign method. Surprisingly, few-layer $\mathrm{Bi}_{2} \mathrm{O}_{3}$ nanosheets are successfully obtained using the sunlight-driven combustion approach. Moreover, the approach developed here is used to synthesize $\mathrm{Bi}_{2} \mathrm{O}_{3} / \mathrm{ZnO}$ heterostructure exhibiting a structure of few-layer $\mathrm{Bi}_{2} \mathrm{O}_{3}$ nanosheets decorated with $\mathrm{ZnO}$ nanoparticles. $\mathrm{Bi}_{2} \mathrm{O}_{3}$ nanosheets and $\mathrm{Bi}_{2} \mathrm{O}_{3} / \mathrm{ZnO}$ heterostructures synthesized by sunlight-driven combustion route exhibit higher photocatalytic activity than their counterparts synthesized by the conventional solution combustion method. This work illuminates a potential cost-effective method to synthesize defective metal oxide nanostructures at scale.
\end{abstract}

\section{INTRODUCTION}

Nanostructured metal oxide semiconductors have impressive momentum in photocatalytic water treatment applications. However, pristine metal oxide photocatalysts suffer from some serious drawbacks, which negatively affect their photocatalytic performance, including short lifetime of photogenerated electrons and holes which are essential for the photocatalytic process and/or wide band gap, which negatively impacts the visible light response. ${ }^{1,2}$ Different approaches have been introduced to overcome these drawbacks, including doping, co-doping, and construction of metal-oxide-based heterostructures. $^{3-7}$

Surface defect engineering approach attracts recent research attention because it provides a platform to overcome the above-mentioned issues without adding any external dopants. $^{8-10}$ In this regard, surface oxygen vacancies $\left(\mathrm{V}_{\mathrm{O}} \mathrm{s}\right)$ increase the valence band maximum (VBM) or decrease the conduction band minimum (CBM) of the defective metal oxides, leading to narrowed band gap and enhanced light absorption of longer wavelength. $\mathrm{V}_{\mathrm{O}} \mathrm{s}$ also work as temporary traps for the photogenerated electrons, suppressing the electron-hole recombination. Moreover, $\mathrm{V}_{\mathrm{O}} \mathrm{s}$ increase the adsorption ability of the defective metal oxides for the $\mathrm{O}_{2}$ and $\mathrm{CO}_{2}$ molecules. ${ }^{11-15}$ Recent reports on this subject also reveal that the $\mathrm{V}_{\mathrm{O}} \mathrm{s}$ are able to dissociate excitons into free electrons and holes leading to higher photocatalytic performance. ${ }^{16}$ All of these remarkable characteristics of $\mathrm{V}_{\mathrm{O}} \mathrm{s}$ substantiate its effect in regulating the photocatalytic activity of metal oxides.

Superior photocatalytic activity for a metal oxide is also attained by reducing its size to the nano range or by creating pores on its surface. ${ }^{17-20}$ Both the size reduction and pore formation are often achieved by chemical or physical

Received: August 10, 2019

Accepted: November 4, 2019

Published: November 25, 2019 
methods. ${ }^{19,21-23}$ However, most of these methods are expensive and time-/energy-consuming. Additionally, generation of $\mathrm{V}_{\mathrm{O}} \mathrm{s}$ is commonly achieved by post-treatment of the synthesized metal oxide, which is further time- and energyconsuming. ${ }^{24}$

Two-dimensional (2D) nanomaterials beyond graphene attracted widespread research attention due to their exceptional chemical and physical properties. ${ }^{25}$ Two-dimensional metal oxide nanosheets are excellent candidates for photocatalytic applications due to their unique geometry with high specific surface area, which provides a large number of photocatalytic reaction sites and enables rapid charge photogeneration and high charge separation and transport efficiency. ${ }^{26}$ In this aspect, $2 \mathrm{D} \mathrm{Bi}_{2} \mathrm{O}_{3}$ nanosheets (pristine, doped, and heterostructures) have been synthesized using different routes and used for photocatalytic applications. ${ }^{27-32}$ However, unscalable and/or unsustainable synthesis methods have been used to synthesize such $2 \mathrm{D}$ materials.

Solution combustion synthesis is a rapid and facile method to synthesize metal oxide nanostructures. In this process, an exothermic reaction takes place between a fuel (e.g., urea and glycine) and an oxidizer (normally metal nitrate), releasing a large amount of gases. Along with its simplicity and rapidity, higher product yield makes the method of solution combustion an ideal synthesis route, especially for industrial applications. In addition, the large volume of gases associated with this method develop a porous structure for the synthesized product. $^{33-38}$

However, solution combustion is not completely reliable as it requires heat energy to initiate the exothermic combustion reaction. Also, applying electrical heating does not produce homogeneous preheating, which negatively affects both the particle size and pore size distribution. ${ }^{33,39,40}$ Moreover, no such solution combustion synthesis routes are reported in the literature to directly produce $\mathrm{V}_{\mathrm{O}} \mathrm{S}$ in metal oxides.

Herein, a solar-driven combustion synthesis to prepare metal oxides is introduced for the first time. A commercial convex lens is used to concentrate the normal sunlight irradiation (see Supporting Information Video 1). Sunlight irradiation initiates the exothermic reaction and creates oxygen vacancies on the metal oxide surface. Direct exposure to sunlight irradiation achieves uniform heating. It is worthy to note that the synthesis takes place at any time on a sunny day irrespective of the sunlight intensity. Moreover, the formation of nanoparticles immediately starts upon exposing the precursor to the sunlight and higher yields are obtained in short time (ca. $5 \mathrm{~s}$ ). The process developed could be of high interest for industrial applications due to its simplicity, rapidity, sustainability, costeffectiveness, and large-scale production. $\mathrm{ZnO}, \mathrm{Fe}_{3} \mathrm{O}_{4}$, and $\mathrm{Bi}_{2} \mathrm{O}_{3}$ are selected as model metal oxides for the synthesis using the introduced method. The selection was based on their wider environmental photocatalytic applications. ${ }^{41-45}$

\section{EXPERIMENTAL SECTION}

2.1. Materials. Zinc nitrate hexahydrate (Alfa Aesar, 99\%), bismuth nitrate pentahydrate (Sigma-Aldrich, 98\%), ferric nitrate nonahydrate (Sigma-Aldrich, $\geq 98 \%$ ), glycine (SigmaAldrich, 99\%), sucrose (Sigma-Aldrich, 99.5\%), 5,5-dimethyl1-pyrroline N-oxide (Sigma-Aldrich, $\geq 97 \%$, DMPO), 2,2,6,6tetramethylpiperidine (Sigma-Aldrich, 98\%, TEMP), and methyl orange (Loba Chemie) were used as received. The water used for synthesis and other experiments was deionized (DI).
2.2. Synthesis. 2.2.1. Synthesis of ZnO. To synthesize $\mathrm{ZnO}$ nanoparticles, $0.297 \mathrm{~g}$ of zinc nitrate hexahydrate (oxidizer) and $0.065 \mathrm{~g}$ of sucrose (fuel) were mixed and ground for $10 \mathrm{~min}$ to obtain a homogeneous mixture. The mixture was exposed to concentrated sunlight. The sunlight intensity at the surface of the mixture was measured to be $\sim 1256 \mathrm{~W} \mathrm{~m}^{-2}$. The reaction started immediately producing very light nanopowder. The synthesis successfully took place in the morning, noon, and afternoon, indicating that a normal sunny day is enough to carry out the synthesis, irrespective of the light intensity. For comparison, $\mathrm{ZnO}$ nanoparticles were synthesized from the same precursor using the conventional solution combustion (CSC) synthesis on a hot plate. The corresponding sample was marked as $\mathrm{ZnO}$-CSC.

$\mathrm{ZnO}$ nanoparticles were also synthesized using the hydrothermal method as follows. About $2.97 \mathrm{~g}$ of $\mathrm{Zn}\left(\mathrm{NO}_{3}\right)_{2} \cdot 6 \mathrm{H}_{2} \mathrm{O}$ was dissolved in $100 \mathrm{~mL}$ of $0.5 \mathrm{M} \mathrm{NaOH}$. The solution was stirred for $40 \mathrm{~min}$ at room temperature and then transferred to a Teflon-lined steel autoclave. The hydrothermal reaction was carried out at $120{ }^{\circ} \mathrm{C}$ for $8 \mathrm{~h}$. Afterward, the autoclave was allowed to cool to room temperature. The product obtained was then washed three times with DI water and dried at $80^{\circ} \mathrm{C}$ for $12 \mathrm{~h}$.

2.2.2. Synthesis of $\mathrm{Fe}_{3} \mathrm{O}_{4}$. To validate the repeatability of the introduced synthesis method, $\mathrm{Fe}_{3} \mathrm{O}_{4}$ nanoparticles were also prepared following the same method. About $4.04 \mathrm{~g}$ of ferric nitrate nonahydrate and $0.95 \mathrm{~g}$ of glycine were ground, and the mixture was exposed to concentrated sunlight irradiation (Video 1). The sunlight intensity at the surface of the mixture was measured to be $\sim 1252 \mathrm{~W} \mathrm{~m}^{-2}$.

2.2.3. Synthesis of Few-Layer $\mathrm{Bi}_{2} \mathrm{O}_{3}$ Nanosheets. To synthesize few-layer $\mathrm{Bi}_{2} \mathrm{O}_{3}$, about $4.85 \mathrm{~g}$ of bismuth nitrate pentahydrate was mixed with $1.14 \mathrm{~g}$ of sucrose. The solid mixture was ground for $10 \mathrm{~min}$ to obtain a homogeneous mixture. The mixture was exposed to concentrated sunlight irradiation (Scheme 1). The sunlight intensity at the surface of the mixture was measured to be $\sim 1264 \mathrm{~W} \mathrm{~m}^{-2}$.

Scheme 1. Schematic Illustration of the Setup of SunlightDriven Combustion (SDC) Synthesis of Metal Oxide Nanostructure

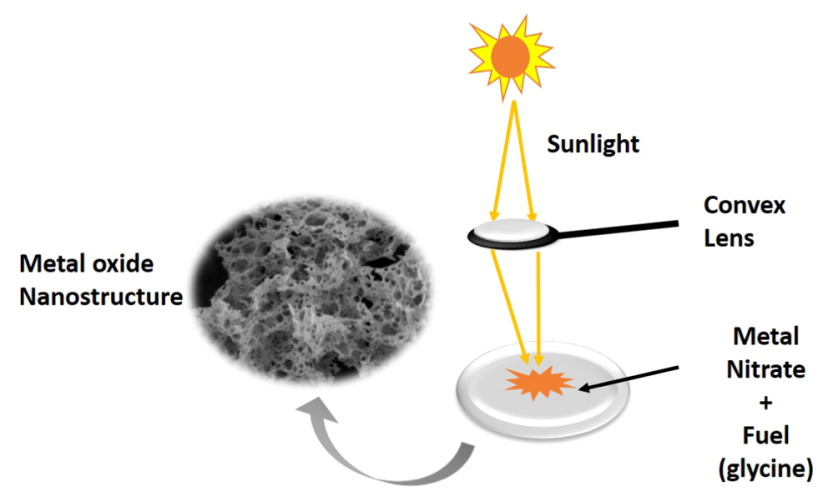

2.2.4. Synthesis of $\mathrm{Bi}_{2} \mathrm{O}_{3} / \mathrm{ZnO}$ Heterostructure. To assure its applicability to synthesize metal oxide heterostructures, $\mathrm{SDC}$ was used to synthesize $\mathrm{Bi}_{2} \mathrm{O}_{3} / \mathrm{ZnO}$ heterostructure. The precursors, bismuth nitrate pentahydrate and zinc nitrate hexahydrate, act as oxidizers, and sucrose as fuel. The Bi-to- $\mathrm{Zn}$ ratio was $1: 0.7$. 


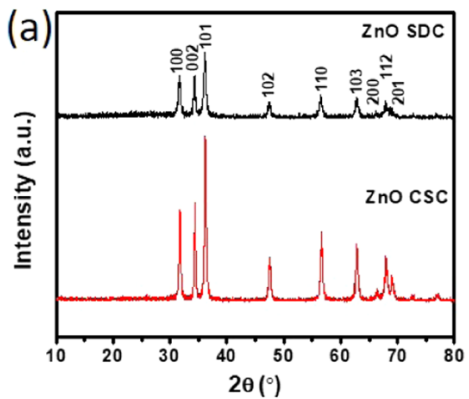

(b)
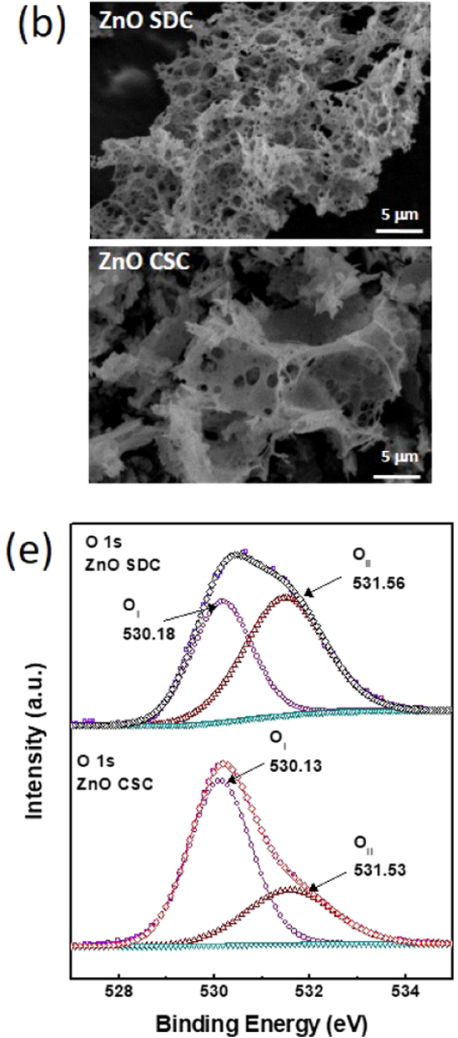

(c)

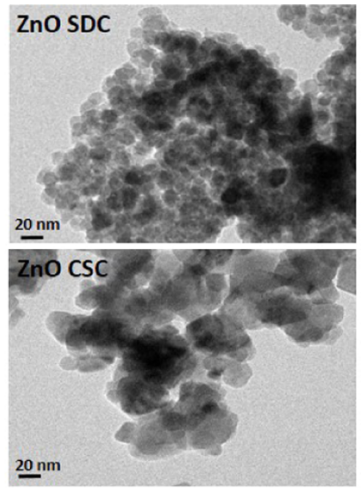

(d)

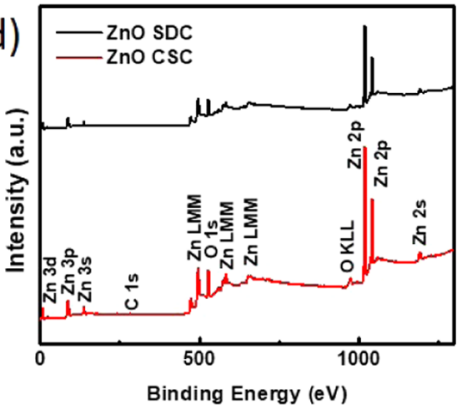

Figure 1. Structural and morphological comparison between $\mathrm{ZnO}$ nanostructure synthesized by sunlight-driven combustion (ZnO SDC) and its counterpart synthesized by a conventional solution combustion method (ZnO CSC). (a) X-ray diffraction (XRD) patterns, (b) scanning electron microscopy (SEM) images, (c) transmission electron microscopy (TEM) images, (d) X-ray photoelectron spectroscopy (XPS) survey spectra, (e) $\mathrm{O}$ 1s XPS images, and (f) $\mathrm{Zn} 2 \mathrm{p}$ XPS images of $\mathrm{ZnO}$ SDC and $\mathrm{ZnO}$ CSC.

2.3. Characterizations. The as-prepared samples were analyzed using a Rigaku Smart Lab II ( $\mathrm{Cu} \mathrm{K} \alpha$ radiation, $\lambda=$ $1.5414 \AA$ A) X-ray diffractometer to study the crystal structure, a Hitachi (S-3400N) scanning electron microscope, and a Jeol/ JEM 2100 transmission electron microscope to investigate the morphology and structure; an ESCALAB 250Xi Thermo Scientific X-ray photoelectron spectroscope was used to analyze the surface electronic states and surface defects; and a Thermo Scientific Evolution 201 UV-vis diffuse reflectance spectrometer was used to record the absorption spectra.

2.4. Photocatalysis Test. For the photodegradation test, the mixture solution of methyl orange (MO, $10 \mathrm{mg} \mathrm{L}^{-1}$ ) or rhodamine $\mathrm{B}\left(\mathrm{RhB}, 10 \mathrm{mg} \mathrm{L}^{-1}\right)$ and the photocatalyst $(0.5 \mathrm{~g}$ $\mathrm{L}^{-1}$ ) was stirred for $30 \mathrm{~min}$ in the dark to ensure the adsorption/desorption equilibrium before sunlight irradiation. The sunlight intensity at the surface of the suspension was measured to be $\sim 335 \mathrm{~W} \mathrm{~m}^{-2}$. The photodegradation of $\mathrm{MO}$ or $\mathrm{RhB}$ was evaluated by monitoring the change in absorbance of mixture solution with a Beckman Coulter DU 730 UV-vis spectrophotometer.

2.5. Mott-Schottky Measurements. To prepare the working electrodes, $5 \mathrm{mg}$ of a photocatalyst was ultrasonically dispersed in $2 \mathrm{~mL}$ of isopropanol alcohol and $40 \mu \mathrm{m}$ Nafion solution. The suspension was spin-coated on FTO glass substrates $\left(1 \times 2 \mathrm{~cm}^{2}\right)$. The coated substrates were dried at ambient temperature in air followed by calcination at $400{ }^{\circ} \mathrm{C}$ for $30 \mathrm{~min}$. A 608E CH instrument was used here to carry out the measurements. A platinum wire and an $\mathrm{Ag} / \mathrm{AgCl}$ electrode were used as counter and reference electrodes, respectively. $\mathrm{Na}_{2} \mathrm{SO}_{4}$ aqueous solution $(0.5 \mathrm{M})$ was used as electrolyte. The recorded potential values were converted to normal hydrogen electrode (NHE) scale. Measurements were recorded at a frequency of $1000 \mathrm{~Hz}$, amplitude of $10 \mathrm{mV}$, and $\mathrm{pH} 7$.

2.6. Electron Spin Resonance (ESR)-Trapping Tests. About $4 \mathrm{~g} \mathrm{~L}^{-1}$ of the sample was suspended in $50 \mu \mathrm{L}$ of DI water followed by addition of $500 \mu \mathrm{L}$ of the spin-trapping agent. The mixture was irradiated for $2 \mathrm{~min}$ and analyzed at the $\mathrm{X}$-band frequency $(9.4 \mathrm{GHz})$ at ambient temperature using a Bruker spectrometer (EMX plus model). The spin-trapping agents were an aqueous solution of TEMP $(10 \mathrm{mM})$ and a methanol solution of DMPO $(20 \mathrm{mM})$ for ${ }^{1} \mathrm{O}_{2}$, and ${ }^{\bullet} \mathrm{O}_{2}$, respectively.

\section{RESULTS AND DISCUSSION}

3.1. Characterizations of $\mathrm{ZnO}$. The sunlight-driven combustion synthesis route is schematically represented in Scheme 1. The convergence of solar radiation to the metal nitrate-glycine mixture and the formation of a porous nanostructure are clear from the scheme. Figures 1 and S1 show the characteristic features of $\mathrm{ZnO}$ prepared by the sunlight-driven combustion ( $\mathrm{ZnO}$ SDC), conventional solution combustion ( $\mathrm{ZnO} \mathrm{CSC})$, and hydrothermal ( $\mathrm{ZnO} \mathrm{Hy})$ routes. The X-ray diffraction (XRD) patterns in Figures 1a and S1a confirm the formation of pure hexagonal wurtzite phase of $\mathrm{ZnO}$ in all three samples (JCPDS 36-1451). ${ }^{46}$ The $\mathrm{ZnO}$ SDC shows lower crystallinity with smaller crystallite size than $\mathrm{ZnO}$ CSC while $\mathrm{ZnO}$ Hy exhibits the highest crystallinity and the largest crystallite size. The scanning electron microscopy (SEM) images show the 3D spongelike structure of both $\mathrm{ZnO}$ SDC and ZnO CSC samples (see Figure 1b) and the irregular- 

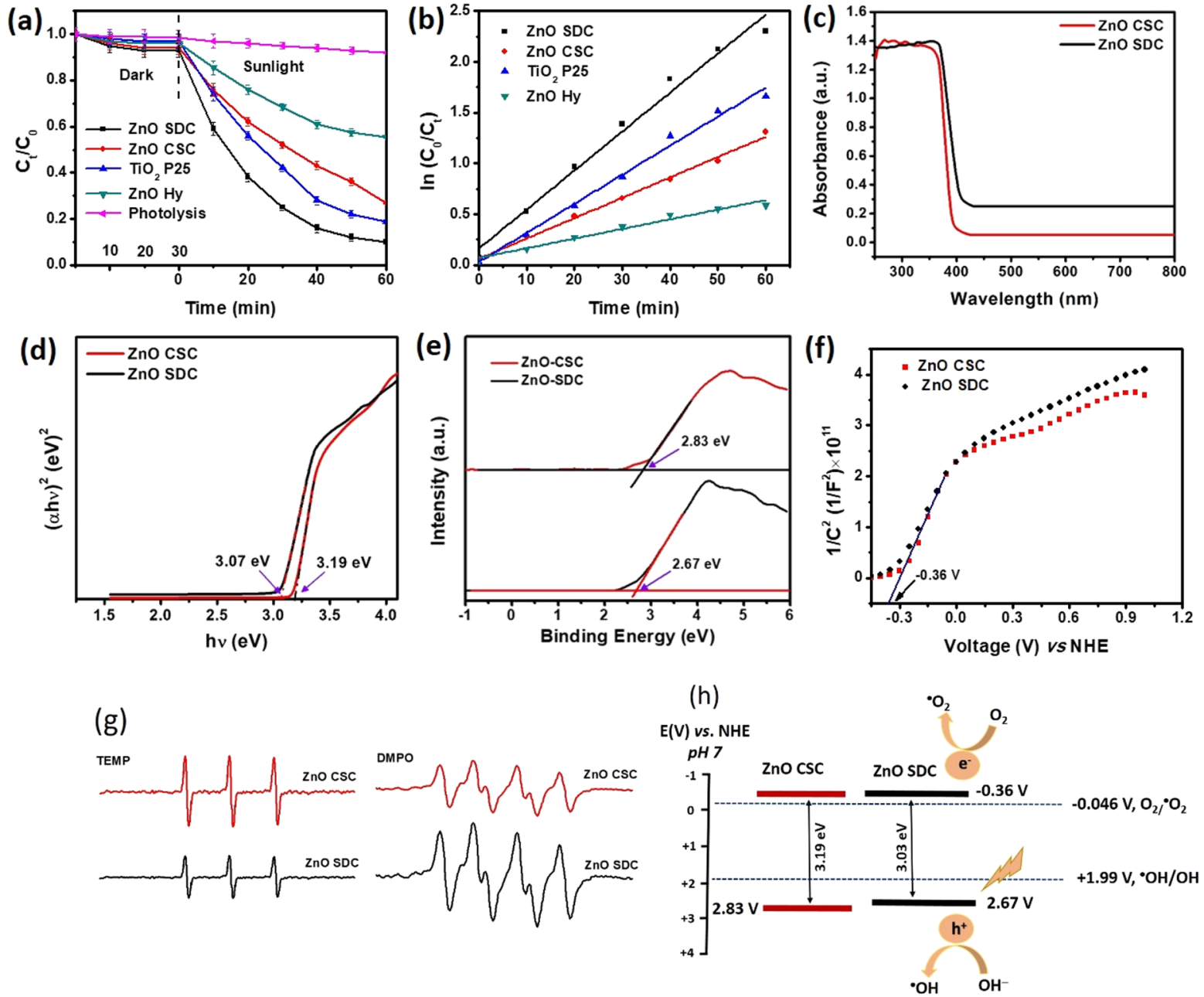

Figure 2. Photocatalytic performance, optical properties, band positions, ESR test, and free radicals production mechanism. (a) Photocatalytic degradation curves of methyl orange (MO, C: initial concentration of $\mathrm{MO}, C_{t}$ : concentration of $\mathrm{MO}$ after $t$ min of sunlight irradiation) and (b) degradation kinetic curves of $\mathrm{MO}$ over $\mathrm{ZnO}$ SDC, $\mathrm{ZnO}$ CSC, and $\mathrm{TiO}_{2}$ Degussa (P25) under sunlight irradiation. (c) Diffuse reflectance spectroscopy (DRS) spectra, (d) Tauc plot, (e) valence band XPS spectra, (f) Mott-Schottky plots at a fixed frequency of $1 \mathrm{kHz}$ in the dark and a potential amplitude of $10 \mathrm{mV}$, (g) ESR spectra in the presence of TEMP in water and in the presence of DMPO in methanol, and (h) schematic diagram of energy band structure and free radicals production during the photocatalysis process for $\mathrm{ZnO}$ CSC and $\mathrm{ZnO}$ SDC.

shaped nanoparticles of $\mathrm{ZnO} \mathrm{Hy}$ (see Figure S1b). Obviously, the $\mathrm{ZnO}$ SDC exhibits a much higher and uniform distribution of pores on its surface compared to $\mathrm{ZnO}$ CSC.

The Brunauer-Emmett-Teller (BET) surface area and pore size distribution of the $\mathrm{ZnO}$ SDC and $\mathrm{ZnO}$ CSC samples were investigated. Both samples exhibit a typical type IV isotherm featuring a pronounced H3-type hysteresis loop demonstrating the existence of mesoporous structure (Figure S2a,b). ${ }^{47}$ The BET surface area was found to be 31.46 and $32.14 \mathrm{~m}^{2} \mathrm{~g}^{-1}$ for $\mathrm{ZnO} \mathrm{CSC}$ and $\mathrm{ZnO}$ SDC, respectively. The Barrett-Joyner-Halender (BJH) pore size distribution graph (inset of Figure S2a) reveals that the $\mathrm{ZnO}$ CSC sample has a broad pore size distribution ranging from 5 to $48 \mathrm{~nm}$. The average pore diameter is measured to be $18.3 \mathrm{~nm}$. For the sample $\mathrm{ZnO} \mathrm{SDC}$, the $\mathrm{BJH}$ pore size distribution was quite narrow (inset of Figure $\mathrm{S} 2 \mathrm{~b}$ ) and the average pore diameter was measured to be $14.8 \mathrm{~nm}$. These results are in good agreement with the SEM observations. It should be mentioned that the sharp peaks at about $3.6 \mathrm{~nm}$ in the pore size distribution curves for both samples are artifacts of the $\mathrm{BJH}$ method due to the tensile strength effect. ${ }^{48,49}$
$\mathrm{ZnO}$ SDC particles are more uniform in size and smaller than the $\mathrm{ZnO} \mathrm{CSC}$, as evident from the TEM image (see Figure 1c). These results can be attributed to the uniform heating induced by the direct exposure of sunlight radiation.

Both $\mathrm{ZnO}$ SDC and $\mathrm{ZnO}$ CSC samples were subjected to XPS analysis to confirm their purity as well as to investigate the presence of surface defects on their structure. Figure $1 \mathrm{~d}$ displays the survey spectra of $\mathrm{ZnO}$ SDC and $\mathrm{ZnO}$ CSC. Only $\mathrm{Zn}, \mathrm{O}$, and a negligible amount of $\mathrm{C}$ are seen in the XPS survey spectra. The $\mathrm{C}$ peak is usually associated with the XPS sample holder. Figure 1e shows a comparison between the highresolution O 1s XPS spectra for $\mathrm{ZnO}$ SDC and $\mathrm{ZnO}$ CSC and their fits. Each O 1s peak is fitted into two peaks: $\mathrm{O}_{\mathrm{I}}(530.18$ and 530.13) is attributed to lattice oxygen and $\mathrm{O}_{\text {II }}(531.56$ and $531.53 \mathrm{eV}$ ) is attributed to $\mathrm{V}_{\mathrm{O}}$ s. Apparently, the $\mathrm{O}_{\mathrm{II}} / \mathrm{O}_{\mathrm{I}}$ intensity ratio for $\mathrm{ZnO} \mathrm{SDC}$ is higher than that of $\mathrm{ZnO}$ $\mathrm{CSC}$, indicating the presence of a higher concentration of $\mathrm{V}_{\mathrm{O}} \mathrm{s}$ in $\mathrm{ZnO} \mathrm{SDC}^{30} \mathrm{Zn} 2 \mathrm{p}$ XPS spectra of both samples show doublet peaks related to $\mathrm{Zn} 2 \mathrm{p}_{3 / 2}$ and $\mathrm{Zn} 2 \mathrm{p}_{1 / 2}$ (see Figure 1f) configurations. $\mathrm{Zn} 2 \mathrm{p}$ of $\mathrm{ZnO}$ SDC shows a downward shift compared to that of $\mathrm{ZnO} \mathrm{CSC}$, further confirming the presence of a considerable concentration of $\mathrm{V}_{\mathrm{O}} \mathrm{s}$ in $\mathrm{ZnO}$ 
SDC. More clearly, the creation of $\mathrm{V}_{\mathrm{O}} \mathrm{s}$ leads to an increase in the electron cloud density, resulting in the downward binding energy shift of $\mathrm{Zn} 2 \mathrm{p}$ peak. ${ }^{51,52}$

How does sunlight create $\mathrm{V}_{\mathrm{O}} \mathrm{s}$ ? It is widely accepted that at atmospheric temperature and pressure, UV-vis photons are able to produce $\mathrm{V}_{\mathrm{O}} \mathrm{s}$ on the surface of metal oxide in the first step of the photothermochemical cycle. ${ }^{53-55}$ The same mechanism is applicable here and thus photons of solar radiation produce $\mathrm{V}_{\mathrm{O}} \mathrm{s}$ on the surface of metal oxide. The following reaction happens on the metal oxide $\left(\mathrm{M}_{x} \mathrm{O}_{y}\right)$ surface when it is exposed to sunlight photons.

$$
\begin{gathered}
2 \mathrm{M}_{x} \mathrm{O}_{y} \rightarrow \underset{x}{2 \mathrm{M}_{x-z} \mathrm{O}_{y-z}+z / 2 \mathrm{O}_{2} \text { (concentrated sunlight }} \text { photons) }
\end{gathered}
$$

Thus, under sunlight irradiation, $\mathrm{M}_{x} \mathrm{O}_{y}$ is reduced to $\mathrm{M}_{x} \mathrm{O}_{y-z}$.

3.2. Photocatalytic Performance and Mechanistic Study. To further demonstrate the advantages of the method developed, the photocatalytic efficacy of $\mathrm{ZnO} \mathrm{SDC}$ is compared to that of $\mathrm{ZnO} \mathrm{CSC}, \mathrm{ZnO} \mathrm{Hy}$ and the standard photocatalyst $\mathrm{TiO}_{2}-\mathrm{P} 25$. Figure 2a depicts the adsorption (in the dark) and photocatalytic degradation of methyl orange (MO) over $\mathrm{ZnO}$ SDC, $\mathrm{ZnO} \mathrm{CSC}, \mathrm{ZnO} \mathrm{Hy}$ and $\mathrm{TiO}_{2}-\mathrm{P} 25$ under natural sunlight irradiation as a function of irradiation time, and Figure $2 \mathrm{~b}$ shows the photodegradation kinetics. A negligible decrease in the MO concentration is observed during the first $20 \mathrm{~min}$ of stirring in the dark because of the dye adsorption on the photocatalysts surfaces. On the other hand, in the absence of any catalyst, only $8 \%$ degradation of MO occurred under sunlight, which can be attributed to photolysis of MO molecules. It can also be seen that $89,81,71$, and $45 \%$ of $\mathrm{MO}$ degraded over $\mathrm{ZnO}$ SDC, $\mathrm{TiO}_{2}-\mathrm{P} 25, \mathrm{ZnO}-\mathrm{CSC}$, and $\mathrm{ZnO} \mathrm{Hy}$, respectively, after $60 \mathrm{~min}$ of sunlight irradiation (Figure 2a). In fact, from Figure $2 \mathrm{~b}$, one can observe that the photodegradation rate constant for $\mathrm{ZnO} \operatorname{SDC}\left(0.038 \mathrm{~min}^{-1}\right)$ is $\sim 4.2$ times that for $\mathrm{ZnO} \mathrm{Hy}\left(0.009 \mathrm{~min}^{-1}\right), \sim 1.9$ times that for $\mathrm{ZnO} \mathrm{CSC}\left(0.02 \mathrm{~min}^{-1}\right)$, and $\sim 1.3$ times that for $\mathrm{TiO}_{2}-\mathrm{P} 25$ $\left(0.029 \mathrm{~min}^{-1}\right)$. Hence, $\mathrm{ZnO}$ SDC exhibits the highest photocatalytic performance.

The durable photostability of the photocatalyst is the key factor for its commercialization. The photostability was examined by recycling $\mathrm{ZnO}$ SDC for four sequential cycles, and the results are displayed in Figure S3a. A negligible decrease in MO degradation was observed after four consecutive cycles, confirming the photostability of $\mathrm{ZnO}$ SDC. To ensure the structural stability of $\mathrm{ZnO}$ SDC, XRD was reexamined before and after the recycling experiments. As shown in Figure S3b, the XRD pattern of $\mathrm{ZnO}$ SDC remains almost the same. Thus, $\mathrm{ZnO}$ SDC is photostable under long sunlight irradiation. This antiphotocorrosion property of $\mathrm{ZnO}$ SDC might be attributed to the presence of a considerable concentration of oxygen vacancies. ${ }^{13,15}$

To understand the mechanism behind the enhanced photocatalytic activity of $\mathrm{ZnO}$ SDC, the optical absorption, band gap, CBM potential, and VBM potential measurements were carried out using diffuse reflectance spectroscopy (UVvis DRS) analysis. Compared to $\mathrm{ZnO} \mathrm{CSC}$, the light absorption of $\mathrm{ZnO}$ SDC is broadened to the visible light region (Figure $2 \mathrm{c}$ ). The band gaps $\left(E_{\mathrm{g}}\right)$ calculated from Tauc plot are 3.07 and $3.19 \mathrm{eV}$ for $\mathrm{ZnO} \mathrm{SDC}$ and $\mathrm{ZnO} \mathrm{CSC}$, respectively (Figure $2 \mathrm{~d}$ ).

$\mathrm{CBM}$ and VBM are calculated according to the following equations $^{56}$

$$
\begin{aligned}
& \mathrm{VBM}=\chi-E_{\mathrm{H}}+0.5 E_{\mathrm{g}} \\
& \mathrm{CBM}=\mathrm{VBM}-E_{\mathrm{g}}
\end{aligned}
$$

where $\chi$ is the $\mathrm{ZnO}$ electronegativity $(5.79 \mathrm{eV})$ and $E_{\mathrm{H}}$ denotes the energy of free electrons on the hydrogen scale $(4.5 \mathrm{eV}) .^{57}$ CBM and VBM are found to be, respectively, ca. -0.31 and $2.89 \mathrm{eV}$ for $\mathrm{ZnO} \mathrm{CSC}$ and ca. -0.25 and $2.83 \mathrm{eV}$ for $\mathrm{ZnO}$ SDC.

VBM and CBM are further experimentally estimated using the Mott-Schottky and valence band XPS (VB-XPS) analyses. VP-XPS measurements show that VBM potential is 2.67 and $2.83 \mathrm{~V}$ for $\mathrm{ZnO}$ SDC and $\mathrm{ZnO} \mathrm{CSC}$, respectively (see Figure 2e). Also, the Mott-Schottky plots displayed in Figure $2 \mathrm{f}$ indicate that both $\mathrm{ZnO} \mathrm{SDC}$ and $\mathrm{ZnO}$ CSC are n-type semiconductors as they have positive slopes. For n-type semiconductors, the Mott-Schottky flat-band potential is approximately equal to that of CBM. Therefore, the CBM potential for both $\mathrm{ZnO}$ SDC and $\mathrm{ZnO} \mathrm{CSC}$ is equal to -0.36 $\mathrm{V}^{58}$

To identify the different photocatalytic reactive oxygen species (ROS) products, electron spin resonance (ESR) measurement was employed. Here, 2,2,6,6-tetramethylpiperidine (TEMP) was used as the trapping reagent to verify the singlet oxygen $\left({ }^{1} \mathrm{O}_{2}\right)$ generation. As displayed in Figure $2 \mathrm{~g}$, the typical 1:1:1 triplet signal with a $g$-value of 2.0056 for both samples $\mathrm{ZnO}$ CSC and $\mathrm{ZnO}$ SDC agrees well with those of 2,2,6,6-tetramethylpiperidine- $N$-oxyl (TEMPO) verifying the ${ }^{1} \mathrm{O}_{2}$ generation by both samples. The stronger ESR signal for $\mathrm{ZnO} \mathrm{CSC}$ confirms its higher ${ }^{1} \mathrm{O}_{2}$ generation. ${ }^{16,59}$ On the other hand, 5,5-dimethyl-1-pyrroline $\mathrm{N}$-oxide (DMPO) was employed as the trapping agent for ${ }^{\bullet} \mathrm{O}_{2}$ detection in methanol. The sextet ESR signal for both samples $\mathrm{ZnO}$ SDC and $\mathrm{ZnO}$ $\mathrm{CSC}$ shown in Figure $2 \mathrm{~g}$ verifies the DMPO-OOH formation, which verifies the ${ }^{\bullet} \mathrm{O}_{2}$ generation by both samples. The stronger ESR signal for the sample $\mathrm{ZnO}$ SDC indicates its higher ${ }^{\bullet} \mathrm{O}_{2}$ production. ${ }^{16}$ Finally, the higher ${ }^{\bullet} \mathrm{O}_{2}$ production and lower ${ }^{1} \mathrm{O}_{2}$ generation exhibited by $\mathrm{ZnO}$ SDC indicate its higher exciton dissociation efficiency, which leads to higher concentration of free electrons and holes and thereby higher photocatalytic performance.

To determine the role of hydroxyl radicals $\left({ }^{\bullet} \mathrm{OH}\right)$ and holes $\left(\mathrm{h}^{+}\right)$in the MO photodegradation, potassium iodide (KI) and tert-butyl alcohol (TBA) were added into photocatalyst/dye suspension as scavengers to trap $\mathrm{h}^{+}$and ${ }^{\circ} \mathrm{OH}$, respectively, followed by the photocatalytic assessments.

It can be seen from Figure S4 that the addition of TBA $\left({ }^{\bullet} \mathrm{OH}\right.$ scavenger) greatly decreased the photocatalytic performance of $\mathrm{ZnO}$ SDC and $\mathrm{ZnO} \mathrm{CSC}$, indicating that ${ }^{\circ} \mathrm{OH}$ is the main active species in the degradation reaction for both samples. In contrast, the MO degradation rate increased in the presence of $\mathrm{KI}\left(\mathrm{h}^{+}\right.$scavenger); about 97 and $71 \%$ of $\mathrm{MO}$ were degraded by $\mathrm{ZnO}$ SDC and $\mathrm{ZnO}$ CSC, respectively, just in 40 min. This finding indicates that the $\mathrm{h}^{+}$consumption in the KI solution suppressed the electron-hole recombination rate. Thus, the MO degradation was enhanced due to the increase in the photogenerated electron concentration. ${ }^{60}$

Based on the above results, the band structure diagrams of $\mathrm{ZnO}$ SDC and $\mathrm{ZnO} \mathrm{CSC}$ are presented in Figure $2 \mathrm{~h}$. The standard redox potential of ${ }^{\bullet} \mathrm{OH} / \mathrm{OH}^{-}$is $+1.99 \mathrm{~V}$ vs NHE, and the standard redox potential of $\mathrm{O}_{2} /{ }^{\bullet} \mathrm{O}_{2}$ is $-0.046 \mathrm{~V}$ vs NHE. ${ }^{61,62}$ One can see that the CBM and VBM potentials for both $\mathrm{ZnO} \mathrm{SDC}$ and $\mathrm{ZnO} \mathrm{CSC}$ are enough to produce 
(a)

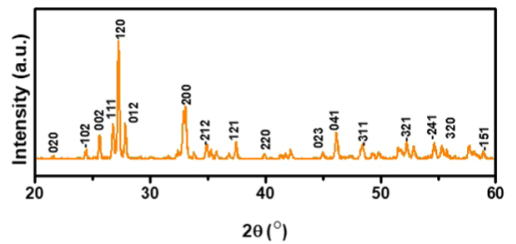

(b)

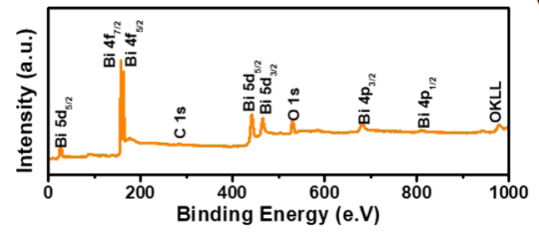

(c)

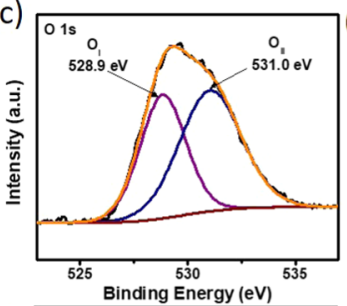

(d)

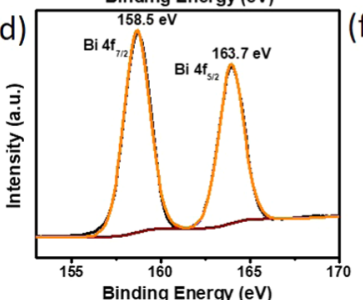

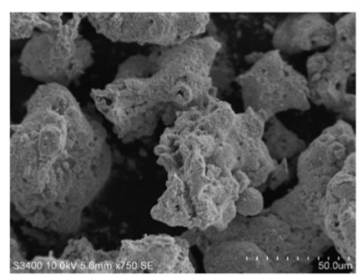

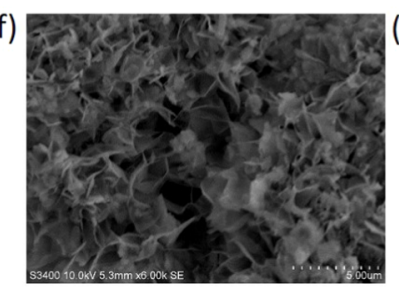

(g)

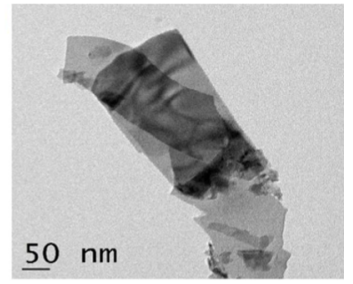

(h)

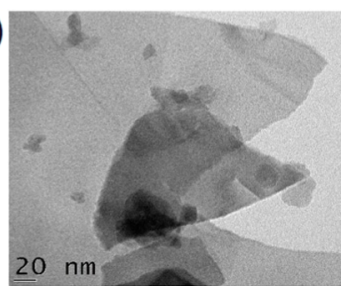

Figure 3. Crystal structure, chemical structure, and morphology of few-layer $\mathrm{Bi}_{2} \mathrm{O}_{3}$. (a) XRD, (b) XPS survey spectrum, (c) O 1s XPS spectrum, (d) $\mathrm{Bi} 4 \mathrm{f} \mathrm{XPS} \mathrm{spectrum,} \mathrm{(e,} \mathrm{f)} \mathrm{SEM} \mathrm{images,} \mathrm{and} \mathrm{(} \mathrm{g}$, h) TEM images of $\mathrm{Bi}_{2} \mathrm{O}_{3}$ synthesized by sunlight-driven combustion method.
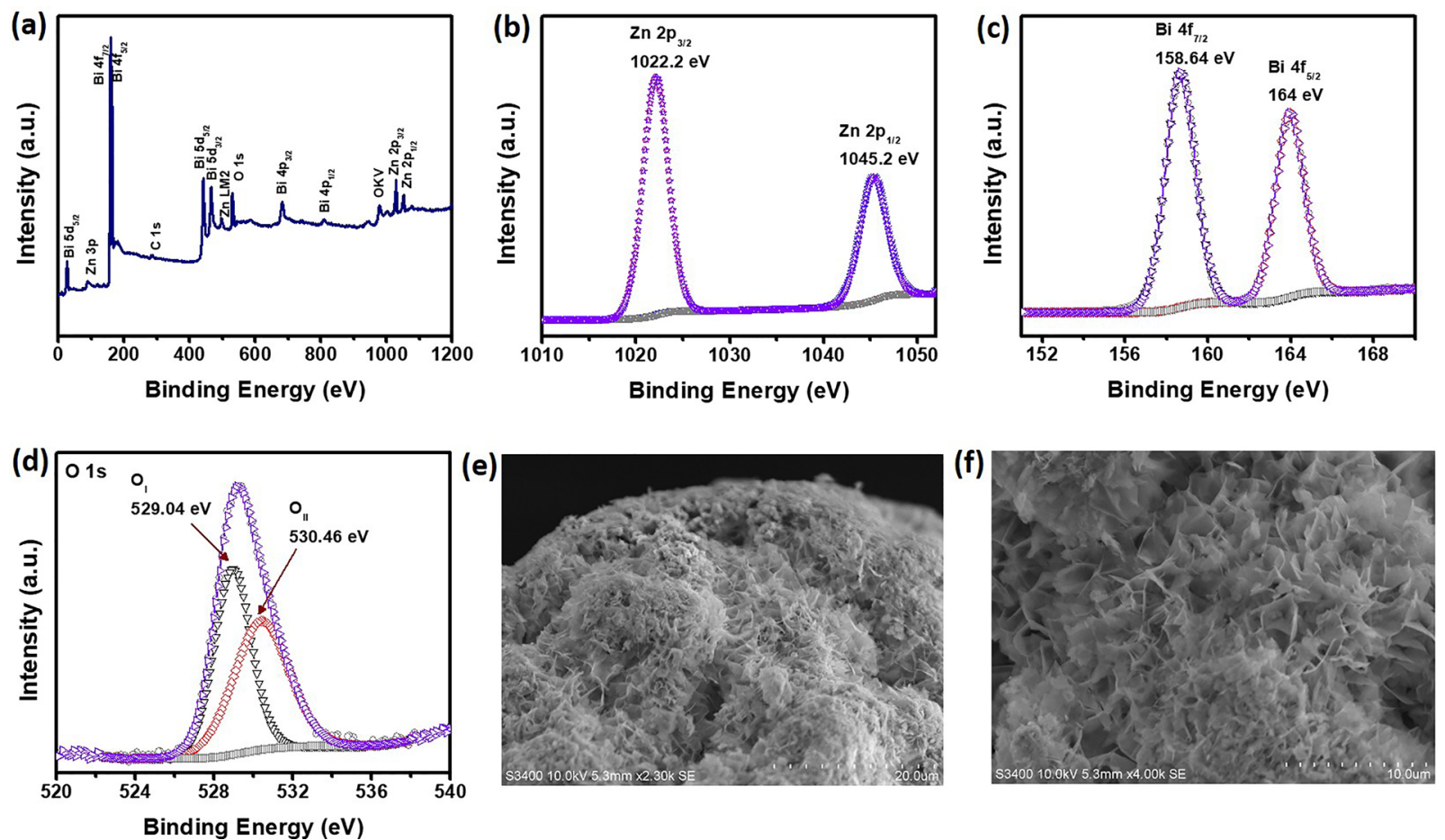

Figure 4. Chemical structure and morphology. (a) XPS survey spectrum, (b) Zn 2p XPS image, (c) Bi 4f XPS spectrum, (d) O 1s XPS spectrum, and $(e, f)$ SEM images of $\mathrm{Bi}_{2} \mathrm{O}_{3} / \mathrm{ZnO}$ heterostructure synthesized by sunlight-driven combustion method.

superoxide $\left({ }^{\circ} \mathrm{O}_{2}\right)$ and hydroxyl $\left({ }^{\circ} \mathrm{OH}\right)$ free radicals. In addition, the VBM for $\mathrm{ZnO}$ SDC is higher than that for $\mathrm{ZnO}$ CSC. This is attributed to the overlapping of $\mathrm{V}_{\mathrm{O}}$ state with VB leading to its upward shift in $\mathrm{ZnO}$ SDC. Generally, the narrower band gap is associated with higher visible light absorption and thereby higher solar photocatalytic activity. Moreover, the presence of a considerable concentration of $\mathrm{V}_{\mathrm{O}} \mathrm{s}$ enhances the photocatalytic activity by lowering the electronhole recombination rate, enhancing the exciton dissociation (as confirmed by ESR), and increasing the $\mathrm{O}_{2}$ adsorption at the defect sites. ${ }^{63,64}$ Besides, the more uniform particle and pore size distribution increase the contact between the nanoparticles and the organic pollutant (MO), leading to the higher photocatalytic activity.
3.3. Repeatability of the Developed Method. Solardriven combustion synthesis is also carried out to test the repeatability and reliability of the method by preparing $\mathrm{Fe}_{3} \mathrm{O}_{4}$. A recorded video demonstrating the simplicity of the method and its potential in synthesizing $\mathrm{Fe}_{3} \mathrm{O}_{4}$ is included as Supporting Information Video 1.

The XRD pattern for sunlight-driven combustion-synthesized $\mathrm{Fe}_{3} \mathrm{O}_{4}$ is shown in Figure S5. The peaks at 30.49, 35.78, $36.28,43.25,53.95,57.27,63.07$, and $74.41^{\circ}$ are related to the (220), (311), (222), (400), (422), (511), (440), and (533) planes of cubic spinel structure of $\mathrm{Fe}_{3} \mathrm{O}_{4}$ (ICDD no. 728151). ${ }^{65}$ The XRD analysis confirms the production of $\mathrm{Fe}_{3} \mathrm{O}_{4}$ by sunlight-driven combustion method. The weak peaks at 37.22 , and $50.19^{\circ}$ are, respectively, related to the (110) and (024) planes of $\alpha-\mathrm{Fe}_{3} \mathrm{O}_{4}$ (ICDD no. 85-0987), ${ }^{65}$ indicating the 
presence of a small of amount of $\alpha-\mathrm{Fe}_{2} \mathrm{O}_{3}$. Figure S6a,b displays the morphology of $\mathrm{Fe}_{3} \mathrm{O}_{4} \mathrm{SDC}$. The porous structure is the signature of released gases during the combustion. The photograph in Figure S6c shows a spongy dark red powder, indicating the presence of a small amount of $\alpha-\mathrm{Fe}_{2} \mathrm{O}_{3}{ }^{66}{ }^{6}$ This supports the XRD analysis. The consistency in the nanostructure formation for both $\mathrm{ZnO}$ and $\mathrm{Fe}_{3} \mathrm{O}_{4}$ confirms the reproducibility of the sunlight-assisted combustion method.

3.4. Synthesis of Few-Layer $\mathrm{Bi}_{2} \mathrm{O}_{3}$ Nanosheets. Surprisingly, we succeeded to synthesize few-layered $\mathrm{Bi}_{2} \mathrm{O}_{3}$ nanosheets using sunlight-driven combustion approach from bismuth nitrate pentahydrate (oxidizer) and sucrose (fuel). The XRD pattern of synthesized $\mathrm{Bi}_{2} \mathrm{O}_{3}$ is presented in Figure $3 \mathrm{a}$, in which the peaks at 21.66, 25.90, 27.00, 27.49, 33.43, $35.2,37.02,46.44,52.59$, and $54.93^{\circ}$ are, respectively, related to the (020), (002), (111), (120), (200), (-212), (121), (041), (-321), (-241) lattice planes of monoclinic $\alpha-\mathrm{Bi}_{2} \mathrm{O}_{3}$ (JCPDS no. 71-2274). ${ }^{41}$ Figure $3 \mathrm{~b}$ shows the XPS survey spectrum of $\mathrm{Bi}_{2} \mathrm{O}_{3}$. All of the peaks are related to $\mathrm{Bi}$ and $\mathrm{O}$ elements except the one at $284.6 \mathrm{eV}$ related to $\mathrm{C} 1 \mathrm{~s}$ from the XPS sample holder confirming the purity of the prepared sample. Figure $3 \mathrm{c}$ shows the high-resolution XPS O 1s spectrum, in which the $\mathrm{O} 1 \mathrm{~s}$ peak is fitted into two peaks at 528.9 and $531.0 \mathrm{eV}$ related to lattice oxygen and $\mathrm{V}_{\mathrm{O}} \mathrm{s}$, respectively. The high-intensity $\mathrm{V}_{\mathrm{O}} \mathrm{s}$ peak indicates that the $\mathrm{Bi}_{2} \mathrm{O}_{3}$ nanosheets are rich in $\mathrm{V}_{\mathrm{O}} \mathrm{s} .{ }^{67}$ These results further support the potential of sunlight-driven combustion method to create oxygen vacancies on the surface of the synthesized oxides. High-resolution XPS $4 \mathrm{f}$ also shows peaks at 158.5 and $163.7 \mathrm{eV}$, respectively, related to $\mathrm{Bi} 4 \mathrm{f}_{7 / 2}$ and $\mathrm{Bi} 4 \mathrm{f}_{5 / 2}$, in agreement with the reported results (Figure $3 \mathrm{~d}$ ). ${ }^{68}$

The SEM images in Figures $3 \mathrm{e}$ and $\mathrm{S} 7$ show the porous structure of $\mathrm{Bi}_{2} \mathrm{O}_{3}$, which is induced by the gas evolution during the combustion. In fact, the porous structure, gained from the gases releasing during the combustion process, is the signature of the combustion synthesis. The higher-resolution SEM image (Figure 3f) shows that the morphology of the asprepared $\mathrm{SDC} \mathrm{Bi}_{2} \mathrm{O}_{3}$ is nanosheets. It is also clear that the nanosheets are well separated. The nonagglomeration of the obtained $\mathrm{Bi}_{2} \mathrm{O}_{3}$ nanosheets may be induced by the gases evolved during the combustion. The TEM images show that the morphology of $\mathrm{SDC} \mathrm{Bi}_{2} \mathrm{O}_{3}$ is a few-layered nanosheets (Figure $3 \mathrm{~g}, \mathrm{~h}$ ). This is yet another advantage achieved during the sunlight-assisted combustion synthesis.

3.5. Sunlight-Driven Synthesis of $\mathrm{Bi}_{2} \mathrm{O}_{3} / \mathrm{ZnO}$ Heterostructure. The proposed sunlight-driven combustion process was also used to prepare $\mathrm{ZnO} / \mathrm{Bi}_{2} \mathrm{O}_{3}$ heterostructure. Later, the heterostructure was characterized by XPS to confirm the interaction between both metal oxides $\left(\mathrm{Bi}_{2} \mathrm{O}_{3}\right.$ and $\left.\mathrm{ZnO}\right)$ and by SEM to determine the morphology. Figure $4 \mathrm{a}$ shows the XPS survey spectrum for the $\mathrm{Bi}_{2} \mathrm{O}_{3} / \mathrm{ZnO}$ heterostructure, in which the $\mathrm{Bi}, \mathrm{Zn}$, and $\mathrm{O}$ peaks are present. The absence of any other elements except a small amount of $\mathrm{C}$ from the sample holder confirms again the phase purity. Figure $4 b-d$ shows the high-resolution XPS spectra of $\mathrm{Zn} 2 \mathrm{p}, \mathrm{Bi} 4 \mathrm{f}$, and $\mathrm{O} 1 \mathrm{~s}$. The peaks at 1022.2 and $1045.2 \mathrm{eV}$ are in agreement with those of $\mathrm{Zn} 2 \mathrm{p}_{3 / 2}$ and $\mathrm{Zn} 2 \mathrm{p}_{1 / 2}$, respectively (Figure $4 \mathrm{~b}$ ). The difference between $\mathrm{Zn} 2 \mathrm{p}_{3 / 2}$ and $\mathrm{Zn} 2 \mathrm{p}_{1 / 2}$ as $23 \mathrm{eV}$ confirms the normal state of $\mathrm{Zn}^{2+}$ in $\mathrm{ZnO}$.

The two signals located at 158.64 and $164 \mathrm{eV}$ correspond to the binding energies of $\mathrm{Bi} 4 \mathrm{f}_{7 / 2}$ and $\mathrm{Bi} 4 \mathrm{f}_{5 / 2}$. Compared to the pristine $\mathrm{Bi}_{2} \mathrm{O}_{3}$ (Section 3.4), $\mathrm{Bi} 4 \mathrm{f}_{7 / 2}$ and $\mathrm{Bi} 4 \mathrm{f}_{5 / 2}$ of $\mathrm{Bi}_{2} \mathrm{O}_{3}$ /
$\mathrm{ZnO}$ heterostructure exhibit a shift to higher binding energy. Such a shift indicates that the photogenerated electrons transfer from $\mathrm{Bi}_{2} \mathrm{O}_{3}$ to $\mathrm{ZnO}$ which is in disagreement with the photogenerated electron transfer in the reported $\mathrm{Bi}_{2} \mathrm{O}_{3} / \mathrm{ZnO}$ heterojunctions. ${ }^{68,69}$ Thus, the sunlight-driven combustionsynthesized $\mathrm{Bi}_{2} \mathrm{O}_{3} / \mathrm{ZnO}$ heterostructure is not a heterojunction system, but it is a direct Z-scheme system. In fact, Z-scheme charge transfer can improve the charge separation and redox ability for the developed material and thereby enhance the photocatalytic activity. ${ }^{70} \mathrm{O} 1 \mathrm{~s}$ was fitted to two peaks at 529.04 and $530.46 \mathrm{eV}$ related to lattice oxygen and oxygen atoms in the vicinity of $\mathrm{V}_{\mathrm{O}}$ s, respectively ${ }^{68}$ (Figure $4 \mathrm{~d}$ ). Thus, XPS analysis confirms the successful formation of $\mathrm{Bi}_{2} \mathrm{O}_{3} / \mathrm{ZnO}$ heterostructure using sunlight-driven solution combustion process. The $\mathrm{ZnO}$ nanoparticles-decorated $2 \mathrm{D}$ nanosheet morphology for the $\mathrm{Bi}_{2} \mathrm{O}_{3} / \mathrm{ZnO}$ heterostructure is represented in Figure 4e,f.

3.6. Photocatalytic Activity of $\mathrm{Bi}_{2} \mathrm{O}_{3}$ Nanosheets and $\mathrm{Bi}_{2} \mathrm{O}_{3} / \mathrm{ZnO}$ Heterostructure. The photocatalytic activity of $\mathrm{Bi}_{2} \mathrm{O}_{3}$ nanosheets and $\mathrm{Bi}_{2} \mathrm{O}_{3} / \mathrm{ZnO}$ heterostructures prepared by sunlight-driven combustion $\left(\mathrm{Bi}_{2} \mathrm{O}_{3} \mathrm{SDC}\right.$ and $\mathrm{Bi}_{2} \mathrm{O}_{3} / \mathrm{ZnO}$ $\mathrm{SDC}$ ) was compared to that of the counterparts synthesized by conventional solution combustion $\left(\mathrm{Bi}_{2} \mathrm{O}_{3} \mathrm{CSC}\right.$ and $\left.\mathrm{Bi}_{2} \mathrm{O}_{3}\right)$ $\mathrm{ZnO} \mathrm{CSC}$ ), and the results are shown in Figure 5a. It can be
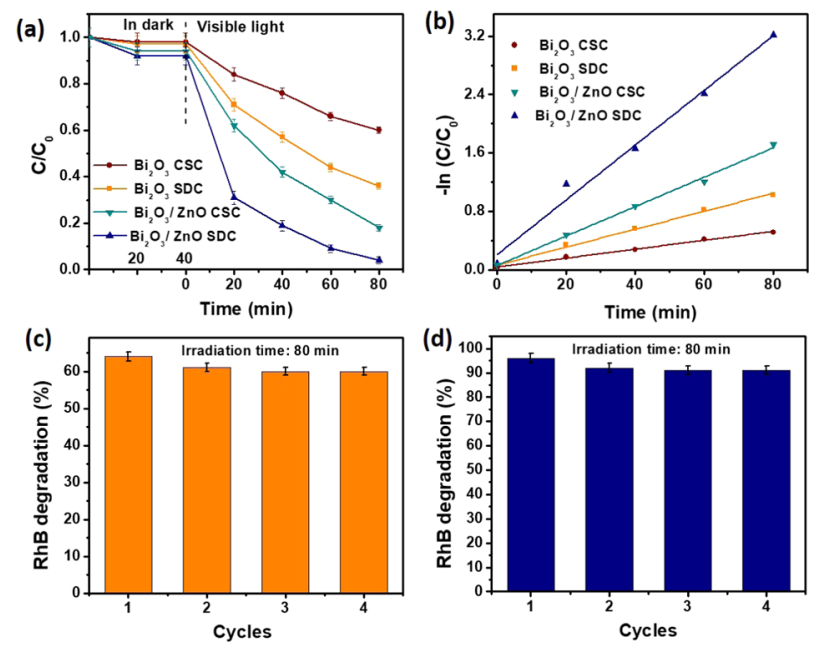

Figure 5. (a) Photocatalytic degradation curves and (b) degradation kinetic curves of $\mathrm{RhB}$ over $\mathrm{Bi}_{2} \mathrm{O}_{3} / \mathrm{ZnO}$ SDC, $\mathrm{Bi}_{2} \mathrm{O}_{3} / \mathrm{ZnO}$ CSC, $\mathrm{Bi}_{2} \mathrm{O}_{3}$ $\mathrm{SDC}$, and $\mathrm{Bi}_{2} \mathrm{O}_{3} \mathrm{CSC}$ under sunlight irradiation, and reusability of (c) $\mathrm{Bi}_{2} \mathrm{O}_{3}$ SDC and (d) $\mathrm{Bi}_{2} \mathrm{O}_{3} / \mathrm{ZnO}$ SDC ( $\mathrm{RhB}$ concentration $=10 \mathrm{mg}$ $\mathrm{L}^{-1}$, catalyst dosage $\left.=0.5 \mathrm{~g} \mathrm{~L}^{-1}, \mathrm{pH} 7\right)$.

seen that about $64,40,96$, and $82 \%$ of $\mathrm{RhB}$ were degraded by $\mathrm{Bi}_{2} \mathrm{O}_{3}$ SDC, $\mathrm{Bi}_{2} \mathrm{O}_{3}$ CSC, $\mathrm{Bi}_{2} \mathrm{O}_{3} / \mathrm{ZnO}$ SDC, and $\mathrm{Bi}_{2} \mathrm{O}_{3} / \mathrm{ZnO}$ $\mathrm{CSC}$, respectively, after $80 \mathrm{~min}$ of sunlight irradiation. To compare the $\mathrm{RhB}$ photodegradation catalyzed by different photocatalysts, the degradation data were fitted according to the pseudo-first-order kinetic model as expressed by eq 4 $(\text { Figure } 5 \mathrm{~b})^{71}$

$$
\ln \left(C / C_{0}\right)=-k t
$$

where $k, C_{0}$, and $C$ are the kinetic rate constant, the $\mathrm{RhB}$ initial concentration, and the $\mathrm{RhB}$ concentration at time $t$, respectively. The $k$ and correlation coefficient $\left(R^{2}\right)$ values are listed in Table 1 . The $R^{2}$ values for all of the samples are more than $98 \%$, indicating that the data fitting using the pseudo-firstorder kinetics model is reasonable. It can also be observed 
Table 1. Kinetics Reaction Constant $(k)$ and Correlation Coefficient $\left(R^{2}\right)$ for $\mathrm{RhB}$ Degradation Catalyzed by $\mathrm{Bi}_{2} \mathrm{O}_{3}$ SDC, $\mathrm{Bi}_{2} \mathrm{O}_{3} \mathrm{CSC}, \mathrm{Bi}_{2} \mathrm{O}_{3} / \mathrm{ZnO} S D C$, and $\mathrm{Bi}_{2} \mathrm{O}_{3} / \mathrm{ZnO} \mathrm{CSC}$

\begin{tabular}{lcl} 
& $R^{2}$ & \multicolumn{1}{c}{$k$} \\
$\mathrm{Bi}_{2} \mathrm{O}_{3} \mathrm{SDC}$ & 0.99284 & 0.0123 \\
$\mathrm{Bi}_{2} \mathrm{O}_{3} \mathrm{CSC}$ & 0.99202 & 0.00611 \\
$\mathrm{Bi}_{2} \mathrm{O}_{3} / \mathrm{ZnO} \mathrm{SDC}$ & 0.98461 & 0.03754 \\
$\mathrm{Bi}_{2} \mathrm{O}_{3} / \mathrm{ZnO}$ CSC & 0.99486 & 0.02016 \\
\hline
\end{tabular}

from Table 1 that the samples prepared by sunlight-driven combustion method $\left(\mathrm{Bi}_{2} \mathrm{O}_{3}\right.$ SDC and $\mathrm{Bi}_{2} \mathrm{O}_{3} / \mathrm{ZnO}$ SDC) exhibit a higher kinetic rate constant than those synthesized by the conventional solution combustion method $\left(\mathrm{Bi}_{2} \mathrm{O}_{3} \mathrm{CSC}\right.$ and $\left.\mathrm{Bi}_{2} \mathrm{O}_{3} / \mathrm{ZnO} \mathrm{CSC}\right)$. These findings further elucidate the importance of the developed synthesis method.

It is clear also that both $\mathrm{Bi}_{2} \mathrm{O}_{3}$ SDC and $\mathrm{Bi}_{2} \mathrm{O}_{3} / \mathrm{ZnO}$ SDC are photostable even after four cycles of photocatalytic degradation of $\mathrm{RhB}$ (Figure $5 \mathrm{c}, \mathrm{d}$ ); no remarkable decrease in the photocatalytic performance was observed after four cycles of RhB degradation under sunlight irradiation.

3.7. Z-Scheme Charge Transport Evidence. XPS analysis indicated that the charge migration follows the Zscheme approach (Section 3.5). Scavengers experiments were used here to further prove the $\mathrm{Z}$-scheme charge transport in $\mathrm{Bi}_{2} \mathrm{O}_{3} / \mathrm{ZnO}$ heterostructure. $p$-Benzoquinone (BQ) and tertbutyl alcohol (TBA) were added into the photocatalyst/dye suspension to trap superoxide radicals $\left({ }^{\bullet} \mathrm{O}_{2}^{-}\right)$and hydroxyl radicals $\left({ }^{\bullet} \mathrm{OH}\right)$, respectively, followed by the photocatalytic assessments. Figure $6 \mathrm{a}$ shows that both $\mathrm{BQ}$ and TBA significantly suppressed the $\mathrm{RhB}$ degradation by $\mathrm{Bi}_{2} \mathrm{O}_{3} / \mathrm{ZnO}$ under sunlight irradiation, indicating that both ${ }^{\circ} \mathrm{O}_{2}{ }^{-}$and ${ }^{\bullet} \mathrm{OH}$ are produced during the photodegrading process.

The positions of CBM and VBM are, respectively, -0.36 and $2.67 \mathrm{~V}$ for $\mathrm{ZnO}$, and 0.18 and $2.92 \mathrm{~V}$ for $\mathrm{Bi}_{2} \mathrm{O}_{3} .{ }^{52}$ If charge transport follows heterojunction approach, the electrons will migrate to $\mathrm{CB}$ of $\mathrm{Bi}_{2} \mathrm{O}_{3}$ and holes to $\mathrm{VB}$ of $\mathrm{ZnO}$ (Figure $6 \mathrm{~b}$ ).
The potential at $\mathrm{CBM}$ of $\mathrm{Bi}_{2} \mathrm{O}_{3}(0.18 \mathrm{~V})$ is not enough to produce ${ }^{\bullet} \mathrm{O}_{2}{ }^{-}$because $\mathrm{O}_{2} /{ }^{\bullet} \mathrm{O}_{2}$ potential is $-0.046 \mathrm{~V}$. Thus, the heterojunction approach cannot explain the production of $\mathrm{O}_{2}{ }^{-}$proved by scavengers experiments. Whereas, if charge transport follows the Z-scheme approach, the electrons will migrate to $\mathrm{CB}$ of $\mathrm{ZnO}$ and the holes will remain in the $\mathrm{VB}$ of $\mathrm{Bi}_{2} \mathrm{O}_{3}$ (Figure 6c). The $\mathrm{CBM}$ of $\mathrm{ZnO}$ has enough potential $(-0.36 \mathrm{~V})$ to produce ${ }^{\circ} \mathrm{O}_{2}{ }^{-}$, which is proved by scavengers experiments. Thus, the $\mathrm{Bi}_{2} \mathrm{O}_{3} / \mathrm{ZnO}$ heterostructure is a $\mathrm{Z}$ scheme system. These results well agree with the XPS analysis.

\section{CONCLUSIONS}

In conclusion, we have developed a novel, facile, and sustainable sunlight-driven combustion method to synthesize porous metal oxide nanostructures. Surprisingly, in this method, the direct exposure to sunlight creates $\mathrm{V}_{\mathrm{O}} \mathrm{s}$ on the surface of oxides and induces homogeneous heating, which facilitates the uniformity in particle size and pore size distribution. UV-vis DRS, Tauc plot, VB-XPS, and MottSchottky analyses indicated that $\mathrm{ZnO}$ SDC has a narrower band gap $(3.07 \mathrm{eV})$ than $\mathrm{ZnO} \mathrm{CSC}(3.19 \mathrm{eV})$. The ESR analysis confirmed that $\mathrm{ZnO}$ SDC exhibits higher exciton dissociation and thereby higher concentration of free electrons and holes than $\mathrm{ZnO}$ CSC. The band gap narrowing and the higher exciton dissociation for $\mathrm{ZnO} \mathrm{SDC}$ were due to the higher concentration of $\mathrm{V}_{\mathrm{O}} \mathrm{s}$ induced by sunlight irradiation. It was also demonstrated that few-layer $\mathrm{Bi}_{2} \mathrm{O}_{3}$ nanosheets and $\mathrm{ZnO} / \mathrm{Bi}_{2} \mathrm{O}_{3}$ heterostructures can be synthesized using the introduced method. $\mathrm{ZnO}, \mathrm{Bi}_{2} \mathrm{O}_{3}$, and $\mathrm{ZnO} / \mathrm{Bi}_{2} \mathrm{O}_{3}$ synthesized by the sunlight-driven combustion method exhibit higher photocatalytic activity than their conventional counterparts. The cost-effectiveness of the sunlight-driven combustion method offers an alternative route for large-scale synthesis of porous metal oxide nanomaterials.

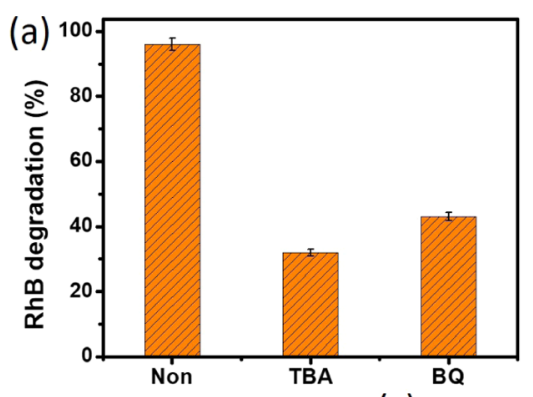

(b)

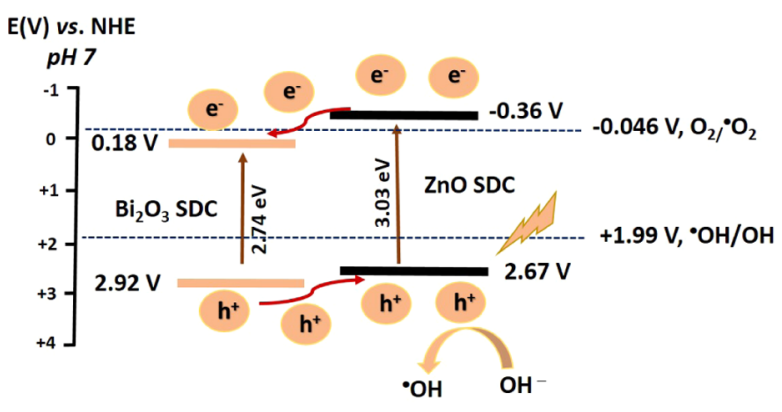

(c)

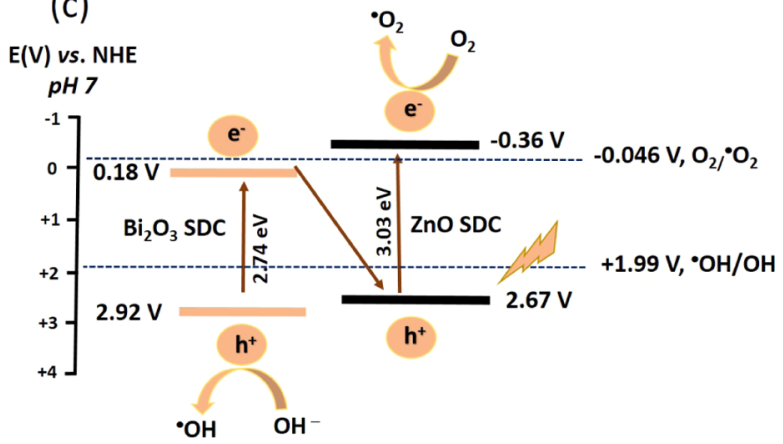

Figure 6. (a) Effect of TBA and $\mathrm{BQ}$ on $\mathrm{RhB}$ degradation over $\mathrm{ZnO} / \mathrm{Bi}_{2} \mathrm{O}_{3} \mathrm{SDC}$ under sunlight irradiation and comparison of charge transport in $\mathrm{Bi}_{2} \mathrm{O}_{3} / \mathrm{ZnO}$ SDC heterostructure based on (b) heterojunction and (c) Z-scheme approaches. 


\section{ASSOCIATED CONTENT}

\section{S Supporting Information}

The Supporting Information is available free of charge at https://pubs.acs.org/doi/10.1021/acsomega.9b02564.

Experiment shows the sunlight-driven synthesis of $\mathrm{Fe}_{3} \mathrm{O}_{4}$ (MP4)

Characterizations of $\mathrm{Fe}_{3} \mathrm{O}_{4}(\mathrm{PDF})$

\section{AUTHOR INFORMATION}

\section{Corresponding Authors}

*E-mail: drmosh@kfupm.edu.sa (Q.A.D.).

*E-mail: kbyrappa@gmail.com (K.B.).

\section{ORCID}

Abdo Hezam: 0000-0002-5876-0868

Kullaiah Byrappa: 0000-0001-6194-9496

\section{Notes}

The authors declare no competing financial interest.

\section{ACKNOWLEDGMENTS}

This study was supported by University Grants Commission, India, under University with Potential for Excellence (UPE) program at University of Mysore, UGC JRF (Award No. F.191/2013(SA-I)), and Deanship of Scientific Research (DSR) at King Fahd University of Petroleum \& Minerals (KFUPM) through project no. DF181021.

\section{REFERENCES}

(1) Malwal, D.; Gopinath, P. Enhanced Photocatalytic Activity of Hierarchical Three Dimensional Metal Oxide@CuO Nanostructures towards the Degradation of Congo Red Dye under Solar Radiation. Catal. Sci. Technol. 2016, 6, 4458-4472.

(2) Kumar, S. G.; Rao, K. K. Comparison of Modification Strategies towards Enhanced Charge Carrier Separation and Photocatalytic Degradation Activity of Metal Oxide Semiconductors $\left(\mathrm{TiO}_{2}, \mathrm{WO}_{3}\right.$ and $\mathrm{ZnO}$ ). Appl. Surf. Sci. 2017, 391, 124-148.

(3) Zhou, W.; Yin, Z.; Du, Y.; Huang, X.; Zeng, Z.; Fan, Z.; Liu, H.; Wang, J.; Zhang, H. Synthesis of Few-Layer $\mathrm{MoS}_{2}$ Nanosheet-Coated $\mathrm{TiO}_{2}$ Nanobelt Heterostructures for Enhanced Photocatalytic Activities. Small 2013, 9, 140-147.

(4) Low, J.; Jiang, C.; Cheng, B.; Wageh, S.; Al-Ghamdi, A. A.; Yu, J. A Review of Direct Z-Scheme Photocatalysts. Small Methods 2017, 1, No. 1700080.

(5) Lee, K. M.; Lai, C. W.; Ngai, K. S.; Juan, J. C. Recent Developments of Zinc Oxide Based Photocatalyst in Water Treatment Technology: A Review. Water Res. 2016, 88, 428-448.

(6) Marschall, R. Semiconductor Composites: Strategies for Enhancing Charge Carrier Separation to Improve Photocatalytic Activity. Adv. Funct. Mater. 2014, 24, 2421-2440.

(7) Wang, H.; Zhang, L.; Chen, Z.; Hu, J.; Li, S.; Wang, Z.; Liu, J.; Wang, X. Semiconductor Heterojunction Photocatalysts: Design, Construction, and Photocatalytic Performances. Chem. Soc. Rev. 2014, 43, 5234.

(8) Bora, T.; Sathe, P.; Laxman, K.; Dobretsov, S.; Dutta, J. Defect Engineered Visible Light Active $\mathrm{ZnO}$ Nanorods for Photocatalytic Treatment of Water. Catal. Today 2017, 284, 11-18.

(9) Jiang, D.; Wang, W.; Zhang, L.; Zheng, Y.; Wang, Z. Insights into the Surface-Defect Dependence of Photoreactivity over $\mathrm{CeO}_{2}$ Nanocrystals with Well-Defined Crystal Facets. ACS Catal. 2015, 5, 4851-4858.

(10) Wang, Z.; Xue, J.; Han, D.; Gu, F. Controllable Defect Redistribution of $\mathrm{ZnO}$ Nanopyramids with Exposed $\{10 \overline{1} 1\}$ Facets for Enhanced Gas Sensing Performance. ACS Appl. Mater. Interfaces 2015, 7, 308-317.

(11) Wang, J.; Wang, Z.; Huang, B.; Ma, Y.; Liu, Y.; Qin, X.; Zhang, X.; Dai, Y. Oxygen Vacancy Induced Band-Gap Narrowing and
Enhanced Visible Light Photocatalytic Activity of ZnO. ACS Appl. Mater. Interfaces 2012, 4, 4024-4030.

(12) Ansari, S. A.; Khan, M. M.; Kalathil, S.; Nisar, A.; Lee, J.; Cho, M. H. Oxygen Vacancy Induced Band Gap Narrowing of ZnO Nanostructures by an Electrochemically Active Biofilm. Nanoscale 2013, 5, 9238.

(13) Lv, Y.; Yao, W.; Ma, X.; Pan, C.; Zong, R.; Zhu, Y. The Surface Oxygen Vacancy Induced Visible Activity and Enhanced UV Activity of a $\mathrm{ZnO}_{1-\mathrm{x}}$ Photocatalyst. Catal. Sci. Technol. 2013, 3, 3136.

(14) Ullattil, S. G.; Periyat, P.; Naufal, B.; Lazar, M. A. Self-Doped ZnO Microrods-High Temperature Stable Oxygen Deficient Platforms for Solar Photocatalysis. Ind. Eng. Chem. Res. 2016, 55, 6413-6421.

(15) Peng, Y.; Wang, Y.; Chen, Q.-G.; Zhu, Q.; Xu, A. W. Stable Yellow ZnO Mesocrystals with Efficient Visible-Light Photocatalytic Activity. Cryst. Eng. Commun. 2014, 16, 7906-7913.

(16) Wang, H.; Yong, D.; Chen, S.; Jiang, S.; Zhang, X.; Shao, W.; Zhang, Q.; Yan, W.; Pan, B.; Xie, Y. Oxygen-vacancy-mediated exciton dissociation in $\mathrm{BiOBr}$ for boosting charge-carrier-involved molecular oxygen activation. J. Am. Chem. Soc. 2018, 140, 17601766.

(17) Mclaren, A.; Valdes-Solis, T.; Li, G.; Tsang, S. C. Shape and Size Effects of $\mathrm{ZnO}$ Nanocrystals on Photocatalytic Activity. J. Am. Chem. Soc. 2009, 131, 12540-12541.

(18) Dodd, A. C.; Mckinley, A. J.; Saunders, M.; Tsuzuki, T. Effect of Particle Size on the Photocatalytic Activity of Nanoparticulate Zinc Oxide. J. Nanopart. Res. 2006, 8, 43-51.

(19) Zhang, G.; Shen, X.; Yang, Y. Facile Synthesis of Monodisperse Porous $\mathrm{ZnO}$ Spheres by a Soluble Starch-Assisted Method and Their Photocatalytic Activity. J. Phys. Chem. C 2011, 115, 7145-7152.

(20) Francavilla, M.; Pineda, A.; Romero, A. A.; Colmenares, J. C.; Vargas, C.; Monteleone, M.; Luque, R. Efficient and Simple Reactive Milling Preparation of Photocatalytically Active Porous $\mathrm{ZnO}$ Nanostructures Using Biomass Derived Polysaccharides. Green Chem. 2014, 16, 2876-2885.

(21) Ong, C. B.; Ng, L. Y.; Mohammad, A. W. A Review of $\mathrm{ZnO}$ Nanoparticles as Solar Photocatalysts: Synthesis, Mechanisms and Applications. Renewable Sustainable Energy Rev. 2018, 81, 536-551.

(22) Tripathy, N.; Ahmad, R.; Kuk, H.; Lee, D. H.; Hahn, Y.-B.; Khang, G. Rapid Methyl Orange Degradation Using Porous ZnO Spheres Photocatalyst. J. Photochem. Photobiol., B 2016, 161, 312317.

(23) Yuan, S.; Zhang, Q.; Xu, B.; Jin, Z.; Zhang, Y.; Yang, Y.; Zhang, M.; Ohno, T. Porous Cerium Dioxide Hollow Spheres and Their Photocatalytic Performance. RSC Adv. 2014, 4, 62255-62261.

(24) Wang, J.; Chen, R.; Xiang, L.; Komarneni, S. Synthesis, Properties and Applications of $\mathrm{ZnO}$ Nanomaterials with Oxygen Vacancies: A Review. Ceram. Int. 2018, 44, 7357-7377.

(25) Vishnoi, P.; Pramoda, K.; Rao, C. N. R. 2D Elemental Nanomaterials beyond Graphene. ChemNanoMat 2019, 1062.

(26) Zhang, Z.; Jiang, D.; Xing, C.; Chen, L.; Chen, M.; He, M. Novel AgI-Decorated $\beta$ - $\mathrm{Bi}_{2} \mathrm{O}_{3}$ Nanosheet Heterostructured Z-Scheme Photocatalysts for Efficient Degradation of Organic Pollutants with Enhanced Performance. Dalton Trans. 2015, 44, 11582-11591.

(27) Zhou, L.; Wang, W.; Xu, H.; Sun, S.; Shang, M. $\mathrm{Bi}_{2} \mathrm{O}_{3}$ Hierarchical Nanostructures: Controllable Synthesis, Growth Mechanism, and Their Application in Photocatalysis. Chem - Eur. J. 2009, $15,1776-1782$.

(28) Li, Y.; Zhang, Z.; Zhang, Y.; Sun, X.; Zhang, J.; Wang, C.; Peng, Z.; Si, H. Preparation of Ag Doped $\mathrm{Bi}_{2} \mathrm{O}_{3}$ Nanosheets with Highly Enhanced Visible Light Photocatalytic Performances. Ceram. Int. 2014, 40, 13275-13280.

(29) Faisal, M.; Ibrahim, A. A.; Bouzid, H.; Al-Sayari, S.; Al-Assiri, M.; Ismail, A. A. Hydrothermal Synthesis of Sr-Doped $\alpha-\mathrm{Bi}_{2} \mathrm{O}_{3}$ Nanosheets as Highly Efficient Photocatalysts under Visible Light. J. Mol. Catal. A: Chem. 2014, 387, 69-75.

(30) Gao, X.; Shang, Y.; Liu, L.; Fu, F. Chemisorption-Enhanced Photocatalytic Nitrogen Fixation via $2 \mathrm{D}$ Ultrathin $\mathrm{p}-\mathrm{n}$ Heterojunction $\mathrm{AgCl} / \delta-\mathrm{Bi}_{2} \mathrm{O}_{3}$ Nanosheets. J. Catal. 2019, 371, 71-80. 
(31) Liu, H.; Luo, M.; Hu, J.; Zhou, T.; Chen, R.; Li, J. $\beta-\mathrm{Bi}_{2} \mathrm{O}_{3}$ and $\mathrm{Er}^{3+}$ Doped $\beta-\mathrm{Bi}_{2} \mathrm{O}_{3}$ Single Crystalline Nanosheets with Exposed Reactive $\{001\}$ Facets and Enhanced Photocatalytic Performance. Appl. Catal., B 2013, 140-141, 141-150.

(32) Liu, W.; Zhou, J.; Hu, Z.; Zhou, J.; Cai, W. In Situ Facile Fabrication of Z-Scheme Leaf-like $\beta-\mathrm{Bi}_{2} \mathrm{O}_{3} / g-\mathrm{C}_{3} \mathrm{~N}_{4}$ Nanosheets Composites with Enhanced Visible Light Photoactivity. J. Mater. Sci.: Mater. Electron. 2018, 29, 14906-14917.

(33) Varma, A.; Mukasyan, A. S.; Rogachev, A. S.; Manukyan, K. V. Solution Combustion Synthesis of Nanoscale Materials. Chem. Rev. 2016, 116, 14493-14586.

(34) Wen, W.; Wu, J.-M. Nanomaterials via Solution Combustion Synthesis: a Step Nearer to Controllability. RSC Adv. 2014, 4, 58090-58100.

(35) Deganello, F.; Tyagi, A. K. Solution Combustion Synthesis, Energy and Environment: Best Parameters for Better Materials. Prog. Cryst. Growth Charact. Mater. 2018, 64, 23-61.

(36) Samu, G. F.; Veres, Á.; Endrődi, B.; Varga, E.; Rajeshwar, K.; Janáky, C. Bandgap-Engineered Quaternary $\mathrm{MxBi}_{2-\mathrm{x}} \mathrm{Ti}_{2} \mathrm{O}_{7}$ (M: Fe, $\mathrm{Mn})$ Semiconductor Nanoparticles: Solution Combustion Synthesis, Characterization, and Photocatalysis. Appl. Catal., B 2017, 208, 148160.

(37) Thoda, O.; Xanthopoulou, G.; Vekinis, G.; Chroneos, A. Review of Recent Studies on Solution Combustion Synthesis of Nanostructured Catalysts. Adv. Eng. Mater. 2018, 20, No. 1800047.

(38) Wen, W.; Yao, J.-C.; Jiang, C.-C.; Wu, J.-M. SolutionCombustion Synthesis of Nanomaterials for Lithium Storage. Int. J. Self-Propagating High-Temperature Synth. 2017, 26, 187-198.

(39) Manikandan, A.; Sridhar, R.; Antony, S. A.; Ramakrishna, S. A simple aloe vera plant-extracted microwave and conventional combustion synthesis: morphological, optical, magnetic and catalytic properties of $\mathrm{CoFe}_{2} \mathrm{O}_{4}$ nanostructures. J. Mol. Struct. 2014, 1076, $188-200$.

(40) Ajamein, H.; Haghighi, M.; Alaei, S. The role of various fuels on microwave-enhanced combustion synthesis of $\mathrm{CuO} / \mathrm{ZnO} / \mathrm{Al}_{2} \mathrm{O}_{3}$ nanocatalyst used in hydrogen production via methanol steam reforming. Energy Convers. Manage. 2017, 137, 61-73.

(41) Sood, S.; Umar, A.; Mehta, S. K.; Kansal, S. K. $\alpha$-Bi2O3 Nanorods: An Efficient Sunlight Active Photocatalyst for Degradation of Rhodamine B and 2,4,6-Trichlorophenol. Ceram. Int. 2015, 41, $3355-3364$.

(42) Hou, J.; Yang, C.; Wang, Z.; Zhou, W.; Jiao, S.; Zhu, H. In Situ Synthesis of $\alpha-\beta$ Phase Heterojunction on $\mathrm{Bi}_{2} \mathrm{O}_{3}$ Nanowires with Exceptional Visible-Light Photocatalytic Performance. Appl. Catal., B 2013, 142-143, 504-511.

(43) Bhuyan, D.; Malakar, B.; Arbuj, S. S.; Saikia, L. Flower Shaped Homocentric Pencil like $\mathrm{ZnO}$ Nanorod Bundles: Synthesis, Characterisation and Study of Their Photocatalytic Activity. RSC Adv. 2014, 4, 8256.

(44) Jang, E. S.; Won, J.-H.; Hwang, S.-J.; Choy, J.-H. Fine Tuning of the Face Orientation of $\mathrm{ZnO}$ Crystals to Optimize Their Photocatalytic Activity. Adv. Mater. 2006, 18, 3309-3312.

(45) Lee, K. M.; Lai, C. W.; Ngai, K. S.; Juan, J. C. Recent Developments of Zinc Oxide Based Photocatalyst in Water Treatment Technology: A Review. Water Res. 2016, 88, 428-448.

(46) Wang, S.; Kuang, P.; Cheng, B.; Yu, J.; Jiang, C. ZnO hierarchical microsphere for enhanced photocatalytic activity. J. Alloys Compd. 2018, 741, 622-632.

(47) Li, Q.; Guo, B.; Yu, J.; Ran, J.; Zhang, B.; Yan, H.; Gong, J. R. Highly Efficient Visible-Light-Driven Photocatalytic Hydrogen Production of CdS-Cluster-Decorated Graphene Nanosheets. J. Am. Chem. Soc. 2011, 133, 10878-10884.

(48) Zhang, J.; Wang, Y.; Zhang, J.; Lin, Z.; Huang, F.; Yu, J. Enhanced Photocatalytic Hydrogen Production Activities of AuLoaded ZnS Flowers. ACS Appl. Mater. Interfaces 2013, 5, 10311037.

(49) Kanyó, T.; Kónya, Z.; Kukovecz, Á.; Berger, F.; Dékány, I.; Kiricsi, I. Quantitative characterization of hydrophilic- hydrophobic properties of MWNTs surfaces. Langmuir 2004, 20, 1656-1661.
(50) Prakash, A.; Bahadur, D. Chemically Derived Defects in Zinc Oxide Nanocrystals and Their Enhanced Photo-Electrocatalytic Activities. Phys. Chem. Chem. Phys. 2014, 16, 21429-21437.

(51) Hosseini, S.; Sarsari, I. A.; Kameli, P.; Salamati, H. Effect of Ag Doping on Structural, Optical, and Photocatalytic Properties of $\mathrm{ZnO}$ Nanoparticles. J. Alloys Compd. 2015, 640, 408-415.

(52) Sahu, R. K.; Ganguly, K.; Mishra, T.; Mishra, M.; Ningthoujam, R.; Roy, S.; Pathak, L. Stabilization of Intrinsic Defects at High Temperatures in $\mathrm{ZnO}$ Nanoparticles by Ag Modification. J. Colloid Interface Sci. 2012, 366, 8-15.

(53) Zhang, Y.; Xu, C.; Chen, J.; Zhang, X.; Wang, Z.; Zhou, J.; Cen, K. A Novel Photo-Thermochemical Cycle for the Dissociation of $\mathrm{CO}_{2}$ Using Solar Energy. Appl. Energy 2015, 156, 223-229.

(54) Ye, L.; Liu, J.; Jiang, Z.; Peng, T.; Zan, L. Facets Coupling of BiOBr-g- $\mathrm{C}_{3} \mathrm{~N}_{4}$ Composite Photocatalyst for Enhanced Visible-LightDriven Photocatalytic Activity. Appl. Catal., B 2013, 142-143, $1-7$.

(55) Zhang, L.; Wang, W.; Jiang, D.; Gao, E.; Sun, S. Photoreduction Of $\mathrm{CO}_{2} \mathrm{On} \mathrm{BiOCl}$ Nanoplates with the Assistance of Photoinduced Oxygen Vacancies. Nano Res. 2015, 8, 821-831.

(56) Xu, C.; Huang, W.; Li, Z.; Deng, B.; Zhang, Y.; Ni, M.; Cen, K. Photothermal Coupling Factor Achieving $\mathrm{CO}_{2}$ Reduction Based on Palladium-Nanoparticle-Loaded $\mathrm{TiO}_{2}$. ACS Catal. 2018, 8, 65826593.

(57) Hezam, A.; Namratha, K.; Drmosh, Q.; Ponnamma, D.; Nagi Saeed, A.; Ganesh, V.; Neppolian, B.; Byrappa, K. Direct Z-Scheme $\mathrm{Cs}_{2} \mathrm{O}-\mathrm{Bi}_{2} \mathrm{O}_{3}-\mathrm{ZnO}$ Heterostructures for Photocatalytic Overall Water Splitting. J. Mater. Chem. A 2018, 6, 21379-21388.

(58) Xia, P.; Zhu, B.; Cheng, B.; Yu, J.; Xu, J. 2D/2D g-C $\mathrm{C}_{3} \mathrm{~N}_{4} / \mathrm{MnO}_{2}$ Nanocomposite as a Direct Z-Scheme Photocatalyst for Enhanced Photocatalytic Activity. ACS Sustainable Chem. Eng. 2018, 6, 965973.

(59) Wang, H.; Jiang, S.; Shao, W.; Zhang, X.; Chen, S.; Sun, X.; Zhang, Q.; Luo, Y.; Xie, Y. Optically Switchable Photocatalysis in Ultrathin Black Phosphorus Nanosheets. J. Am. Chem. Soc. 2018, 140, 3474-3480.

(60) Ebrahimi, M.; Samadi, M.; Yousefzadeh, S.; Soltani, M.; Rahimi, A.; Chou, T. C.; Chen, L. C.; Chen, K. H.; Moshfegh, A. Z. Improved Solar-Driven Photocatalytic Activity of Hybrid Graphene Quantum Dots/ZnO Nanowires: A Direct Z-Scheme Mechanism. ACS Sustainable Chem. Eng. 2017, 5, 367-375.

(61) Ye, L.; Liu, J.; Jiang, Z.; Peng, T.; Zan, L. Facets Coupling of BiOBr-g- $\mathrm{C}_{3} \mathrm{~N}_{4}$ Composite Photocatalyst for Enhanced Visible-LightDriven Photocatalytic Activity. Appl. Catal., B: Environ. 2013, 142143, $1-7$.

(62) Bai, Y.; Wang, P.; Liu, J.; Liu, X. Enhanced Photocatalytic Performance of Direct Z-Scheme BiOCl-g- $\mathrm{C}_{3} \mathrm{~N}_{4}$ Photocatalysts. RSC Adv. 2014, 4, 19456.

(63) Ma, Z.; Li, P.; Ye, L.; Zhou, Y.; Su, F.; Ding, C.; Xie, H.; Bai, Y.; Wong, P. Oxygen Vacancies Induced Exciton Dissociation of Flexible BiOCl Nanosheets for Effective Photocatalytic $\mathrm{CO}_{2}$ Conversion. J. Mater. Chem. A 2017, 5, 24995-25004.

(64) Hezam, A.; Namratha, K.; Drmosh, Q.; Lakshmeesha, T.; Srikantaswamy, S.; Byrappa, K. The Correlation among Morphology, Oxygen Vacancies and Properties of Zno Nanoflowers. J. Mater. Sci.: Mater. Electron. 2018, 29, 13551-13560.

(65) Gandha, K.; Mohapatra, J.; Hossain, M.; Elkins, K.; Poudyal, N.; Rajeshwar, K.; Liu, J. Mesoporous Iron Oxide Nanowires: Synthesis, Magnetic and Photocatalytic Properties. RSC Adv. 2016, 6, 90537-90546.

(66) Wang, X.; Qin, M.; Fang, F.; Jia, B.; Wu, H.; Qu, X.; Volinsky, A. Effect of Glycine on One-Step Solution Combustion Synthesis of Magnetite Nanoparticles. J. Alloys Compd. 2017, 719, 288-295.

(67) Chen, S.; Wang, H.; Kang, Z.; Jin, S.; Zhang, X.; Zheng, X.; Qi, Z.; Zhu, J.; Pan, B.; Xie, Y. Oxygen Vacancy Associated SingleElectron Transfer for Photofixation of $\mathrm{CO}_{2}$ to Long-Chain Chemicals. Nat. Commun. 2019, 10, No. 788.

(68) Yi, S.; Yue, X.; Xu, D.; Liu, Z.; Zhao, F.; Wang, D.; Lin, Y. Study on photogenerated charge transfer properties and enhanced 
visible-light photocatalytic activity of p-type $\mathrm{Bi}_{2} \mathrm{O}_{3} / n$-type $\mathrm{ZnO}$ heterojunctions. New J. Chem. 2015, 39, 2917-2924.

(69) Hezam, A.; Namratha, K.; Ponnamma, D.; Drmosh, Q. A.; Saeed, A. M. N.; Cheng, C.; Byrappa, K. Direct Z-scheme $\mathrm{Cs}_{2} \mathrm{O}-$ $\mathrm{Bi}_{2} \mathrm{O}_{3}-\mathrm{ZnO}$ heterostructures as efficient sunlight-driven photocatalysts. ACS Omega 2018, 3, 12260-12269.

(70) Zhang, Z.; Huang, J.; Fang, Y.; Zhang, M.; Liu, K.; Dong, B. A nonmetal plasmonic Z-scheme photocatalyst with UV- to NIR-driven photocatalytic protons reduction. Adv. Mater. 2017, 29, No. 1606688. (71) Liu, Y.; Jin, W.; Zhao, Y.; Zhang, G.; Zhang, W. Enhanced Catalytic Degradation of Methylene Blue by $\alpha-\mathrm{Fe}_{2} \mathrm{O}_{3} /$ Graphene Oxide via Heterogeneous Photo-Fenton Reactions. Appl. Catal., B 2017, 206, 642-652. 